\title{
RANCANG BANGUN MEDIA DESAIN KATALOG PENUNJANG INFORMASI DAN PROMOSI PT GLOBAL BANGUN MANDIRI
}

\author{
Wahyu Hidayat $^{1}$, Andriansyah ${ }^{2}$, Reni Wulandari ${ }^{3}$ \\ 1,2,3 Jurusan Teknik Informatika, STMIK Raharja \\ 1,2,3 Jl. Jenderal Sudirman No 40 Modern Cikokol Tangerang \\ Email : ${ }^{1}$ wahyu.hidayat@ raharja.info, ${ }^{2}$ andriansyah@ raharja.info, ${ }^{3}$ reni.wulandari@ raharja.info
}

\begin{abstract}
The development of communication media and information today due to the many information needed by everyone, so the information makers continue to be encouraged to make changes to follow the demands of the times. Where many parties are involved, either directly related to the delivery process, or the acceptance of such information. This information delivery model and system will determine whether the process is working properly. One form of media that is considered effective and can be used as a support in the program information and promotion is through a visual communication or through a catalog. Design Catalog is a way an institution or company commonly used as a sign of identity in doing a good communication and within the internal scope of the company and with colleagues, business partners, or other relevant parties. This study aims to apply the concept of Catalog Catalog media to provide information and more effective promotion of the company's products. Currently PT Global Bangun Mandiri is a company engaged in the field of property where many companies are moving companies together and certainly a competitor. To obtain the necessary data during the research, the author uses several methodologies, among others: problem analysis methods, data collection methods (observation, interview, literature study), design analysis methods, and design concepts. The final result of this research is in the form of Design of Catalog Form media which is expected to deliver effective information and promotion message made with interesting layout with a more visual appearance and easy to understand.
\end{abstract}

Keywords: Media, Information, Promotion, Design Catalog

\begin{abstract}
ABSTRAK
Berkembangnya media komunikasi dan informasi saat ini dikarenakan banyaknya informasi yang dibutuhkan oleh semua orang, sehingga para pembuat informasi terus terpacu untuk melakukan perubahan untuk mengikuti tuntutan jaman. Dimana banyak pihak-pihak yang terlibat, baik yang berhubungan langsung dalam proses penyampaian, maupun penerimaan informasi tersebut. Model dan sistem penyampaian informasi ini akan menentukan, apakah proses tersebut berjalan dengan baik dan efektif. Salah satu bentuk media yang dinilai efektif dan dapat dijadikan penunjang dalam program informasi dan promosi yaitu melalui sebuah komunikasi visual atau melalui katalog. Desain Katalog adalah sebuah cara suatu lembaga atau perusahaan yang biasa digunakan sebagai tanda pengenal dalam melakukan komunikasi yang baik dan dalam lingkup intern perusahaan maupun dengan kolega, mitra usaha, ataupun pihak-pihak terkait lainnya. Penelitian ini bertujuan untuk menerapkan konsep media Desain Katalog dapat memberikan informasi dan promosi yang lebih efektif mengenai produk perusahaan. Saat ini PT Global Bangun Mandiri merupakan perusahaan yang bergerak di bidang property dimana banyak perusahaan perusahaan yang bergerak sama dan tentunya menjadi pesaing. Untuk memperoleh data-data yang diperlukan selama penelitian, penulis menggunakan beberapa metodologi, antara lain: metode analisa permasalahan, metode pengumpulan data (observasi, interview, studi pustaka), metode analisa perancangan, dan konsep desain. Hasil akhir dari penelitian ini adalah berupa rancangan media desain berbentuk katalog yang diharapkan dapat menyampaikan pesan informasi dan promosi yang efektif dibuat dengan layout menarik dengan tampilan yang lebih Visual dan mudah dimengerti.
\end{abstract}

Kata kunci : Media, Informasi, Promosi, Desain Katalog 


\section{PENDAHULUAN}

Menggunakan media desain sebagai sarana informasi ataupun sosialisasi yang baik dalam menyampaikan promosi kemasyarakat luas adalah sesuatu yang sangat penting. Promosi sangat berperan penting dalam dunia bisnis, karena promosi suatu kegiatan yang dilakukan untuk mempertahankan perkembangan perusahaan dan untuk mencapai tujuan perusahaan. Dalam dunia bisnis yang berkaitan dengan properti mempromosikan suatu produk sangatlah penting, promosi berperan menyebarkan informasi dan mempengaruhi calon pembeli sehingga mereka tertarik dan berminat untuk membeli produk tersebut. Banyaknya perusahaan bisnis dibidang properti yang ada di Indonesia, Hal ini menyebabkan timbulnya persaingan antara perusahaan properti satu dengan perusahaan-perusahaan properti lain dalam menarik minat calon pembeli. Perusahaan perusahaan yang bergerak di bidang properti beragam dan memiliki daya tarik tersendiri. Persaingan yang timbul secara tidak langsung mengharuskan setiap perusahaan melakukan promosi kebanyak tempat sehingga dapat menjangkau banyak calon pembeli. Promosi biasanya dilakukan di dalam mall-mall dengan membuka stand, diluar atau pinggir jalan dengan membagikan selebaran ke tiap-tiap pengguna kendaraan yang lewat dan semuanya tersebar secara luas diberbagai tempat strategis yang ada di Indonesia.

Pada perusahaan PT Global Bangun Mandiri media informasi dan promosi yang berjalan saat ini hanya ada katalog yang ada di web dan perlu jaringan internet untuk mengaksesnya, hal ini menyebabkan konsumen tidak mengetahui lebih jelas mengenai produk yang dihasilkan oleh perusahaan tersebut. Dilain sudut perusahaan PT Global Bangun Mandiri sebelumnya hanya menargetkan produk bisa dinikmati untuk kalangan menengah keatas. Padahal itu merupakan salah satu faktornya ketidak stabilan pendapatan perusahaan mengingat sekarang semua kalangan baik atas maupun bawah sudah konsumtif terhadap jual beli.

Sehubungan dengan kegiatan promosi yang dilakukan baik didalam ruangan maupun luar ruangan tersebut, maka perusahaan harus tepat dalam menentukan posisi tempat lokasi promosi agar tidak salah sasaran. Penentuan dilakukan tidak sembarang dalam memilih lokasi atau tempat tapi berdasarkan tim survei lapangan yang sebelumnya sudah mengadakan observasi. Agar nantinya semua produk yang dipromosikan menggunakan media desain katalog dapat mencapai target penjualan maksimal.

\section{PERUMUSAN MASALAH}

Yang menjadi perumusan masalah dalam penelitian ini adalah

1. Media apa yang tepat untuk mempromosikan produk PT Global Bangun Mandiri ?

2. Bagaimana merancang media komunikasi dengan menggunakan desain berbentuk katalog sebagai media informasi dan promosi ?

3. Manfaat seperti apa yang didapat setelah menggunakan desain katalog sebagai media penunjang informasi dan promosi pada PT Gobal Bangun Mandiri ?

\section{KAJIAN PUSTAKA}

\section{Pengertian Media}

Media adalah sarana untuk menyimpan pesan atau informasi kepada public dengan menggunakan berbagai unsur komunikasi grafis seperti teks atau gambar/foto.[1]

Media adalah segala bentuk yang digunakan untuk menyalurkan informasi. Pengertian media yang diberikan AECT (Association for Education Communication and Tecnology) ini menunjukkan bahwa istilah "media" memiliki makna yang sangat umum.[2]

Media dapat disimpulkan sebagai sarana perantara yang dipergunakan untuk menyampaikan pesan dari pengirim pesan kapada penerima pesan.

\section{Definisi Desain}

Istilah desain sendiri secara etimologi berasal dari beberapa serapan bahasa yang diambil dari bahasa Itali yaitu "Designo" yang secara gramatikal berarti gambar. Kata desain tersebut dapat digunakan pada berbagai kalimat, baik sebagai kata benda maupun kata kerja. Apabila sebagai kata kerja, istilah "desain" dapat diartikan sebagai proses dalam membuat atau menciptakan 
sebuah objek baru. Sedangkan dalam kata benda istilah "desain" dapat digunakan sebagai hasil akhir dari sebuah proses kreatif, baik itu berwujud sebuah rencana, proposal, atau berbentuk karya nyata.[3]

\section{METODE PENELITIAN}

Untuk memperoleh dan melengkapi data-data yang diperlukan dalam penelitian terkait dengan ini maka digunakan beberapa metode.

Adapun metode yang digunakan adalah sebagai berikut :

1) Analisa permasalahan

Analisis permasalahan di dapatkan pada saat penulis melakukan pertemuan dengan Stakeholdeer melalui tanya jawab dan interview.

2) Pengumpulan Data

a) Metode Observasi

Observasi dilakukan di PT Global Bangun Mandiri untuk pengambilan data yang diperlukan untuk perancangan media desain sebagai penunjang informasi dan promosi melalui pengamatan dan membuat pencatatan secara sistematik terhadap unsur-unsur yang telah diteliti dengan tujuan secara langsung.

b) Metode Wawancara (interview)

Wawancara adalah salah satu metode pengumpulan data dengan cara bertatap muka langsung dengan orang yang akan diwawancarai, memperoleh informasi dan gambaran mengenai media penunjang Promosi dengan jelas seperti apa yang diinginkan.

c) Studi Pustaka

Studi pustaka adalah pengumpulan data-data berupa teori, mempelajari dan memahami bukubuku. Penelitian yang digunakan untuk mendapatkan data yang akurat berdasarkan pada bukubuku, jurnal, dan media tertulis lain yang berkaitan dengan penelitian

3) Metode Analisa perancangan

Perancangan media desain sebagai penunjang informasi dan promosi dirancang berdasarkan analisa terhadap media yang telah digunakan pada media sebelumnya, selain dari itu juga terhadap analisa kebutuhan yang diajukan kepada stakeholder, selanjutnya dirancang menggunakan aplikasi program komputer grafis. Media-media yang akan digunakan sebagai sarana penunjang informasi Pt Global Bangun Mandiri dirancang dengan menggunakan aplikasi Adobe Ilustrator CS6 dan Adobe Photoshop CS6.

4) Metode Konsep Desain

Akan disampaikan tahapan-tahapan proses konsep desain, yaitu :

a. Perencanaan media

Perencanaan Media merupakan kegiatan yang sangat penting dalam periklanan dan promosi. Perencanaan media yang dipersiapkan secara baik akan menghasilkan komunikasi yang efektif sehingga pesan yang terdapat pada produk akan tersampaikan.

b. Perencanaan pesan

Perencanaan Pesan adalah proses komposisi penyusunan pesan bisnis.

c. Perencanaan visual

Perencanaan Visual adalah proses penataan produk yang hendak kita mau promosikan dengan menggunakan media visual sebagai sarananya dan dibantu dengan menggunakan softwaresoftware desain.

\section{LITERATURE REVIEW}

1. Penelitian yang dilakukan oleh Mukadar (2016) dengan judul "Redesain Environmental Graphic Taman Bungkul Surabaya Dengan Teknik Vektor Sebagai Upaya Optimalisasi Media Informasi”. Penelitian ini bertujuan untuk mempermudah pengunjung yang datang di Taman Bungkul Surabaya untuk mendapatkan informasi mengenai kegiatan dan fasilitas yang tersedia dengan menggunakan media desain grafis. Metode yang digunakan, yaitu: Kualitatif untuk menentukan cara mencari, mengumpulkan, mengolah dan menganalisis data. Media utama yang digunakan adalah signage dan wayfinding, seta media pendukungnya adalah Wayfinding Map, Mini-Guide 


\section{Map, dan Mobile Wayfinding Devices.[4]}

2. Penelitian yang dilakukan oleh Lifenia (2013) dengan judul "Perancangan Media Promosi Triwulan EventArtotel Surabaya". Penelitian ini bertujuan untuk memperkenalkan Triwulan Event sehingga dengan adanya promosi yang efektif maka diharapkan akan membuat masyarakat datang berkunjung ke Artotel untuk melihatTriwulan Event yang berada di lobi Artotel. Metode yang digunakan, yaitu: Komunikasi Visual menggunakan metode analisis SWOT (Strength, Weakness, Opportunities, Threats). Aplikasi media promosi yang digunakan untuk menjangkau target market melalui beberapa media antara lain: poster, X-banner, kalender, brosur, gantungan kunci, dan placemat akan tersampaikan dengan baik.[5]

\section{HASIL DAN PEMBAHASAN}

\section{Perencanaan Media}

Dalam hal ini, konsep media yang diajukan adalah perancangan Media Desain dalam bentuk Katalog. Katalog ini berisi tentang Produk-produk yang dipasarkan oleh PT Global Bangun Mandiri. Semua isi yang terkait dalam pembuatan Media Desain Katalog tersebut dikemas dengan menggunakan pengembangan kreatif desain grafis. Oleh karena itu untuk membantu dalam pengembangan pengemasan produk agar kreatif dan grafis dibantu menggunakan software Adobe Ilustrator dan Adobe Photoshop.

\section{Tujuan Media}

Tujuan dari perancangan media desain katalog ini adalah sebagai salah satu sarana media informasi untuk mempromosikan produk perusahaan kepada konsumen atau relasi bisnis khususnya perusahaanperusahaan yang memerlukan produk properti dari PT Global Bangun Mandiri.

Perancangan Media desain Katalog ini harus mencakup 70\% dari khalayak sasaran yang menargetkan produk tersebut bisa dibeli oleh kalangan menengah kebawah, dimana pada target sebelumnya hanya untuk kalangan menengah keatas. Media informasi dan sarana komunikasi ini digunakan selama kondisi PT Global Bangun Mandiri tidak mengalami perubahan baik strategi maupun manajemen. Sehingga dari tujuan tersebut nantinya bisa meningkatkan penjualan setiap bulannya, mengingat semakin maraknya bisnis property saat ini dan semakin konsumtifnya daya beli masyarakat melalui hasil survey lebih banyak dikalangan orang menengah kebawah.

\section{Strategi Media}

Sebelum melakukan proses desain, penulis terlebih dahulu merumuskan strategi media. Dimana strategi media ini menetapkan dua hal yaitu siapa sasarannya dan bagaimana cara mencapai sasaran tersebut. Adapun sasaran dari perancangan media desain katalog adalah untuk memenuhi 3 (tiga) aspek sasaran yaitu :

$$
\begin{array}{llll}
\text { Geografi : Jakarta, Indonesia } & & \\
\text { Demografi: } & - \text { Jenis Kelamin } & : & \text { Pria \& Wanita } \\
& - \text { Kelas Ekonomi }: & \text { Menengah Keatas } \\
& - \text { Sasaran } & : & \text { 1. Relasi Perusahaan } \\
& & & \text { 2. Konsumen } \\
& & & \text { 3. Masyarakat }
\end{array}
$$

Psikografi : Konsumen, Relasi Perusahaan, dan Masyarakat yang ingin lebih mengetahui informasi mengenai produk PT Global Bangun Mandiri.

Selain itu, untuk mencapai sasaran diatas sehingga tercapainya tingkat yang dinyatakan dalam tujuan media, maka ditetapkanlah dua hal yaitu apa yang menjadi media utama dan media penunjang.

\section{Program Media}

Rencananya Media Desain Katalog sebagai informasi dan promosi ini mulai digunakan awal tahun 2018 dengan jadwal promosi dalam jangka panjang yang disesuaikan dengan kondisi dan perkembangan dari PT Global Bangun Mandiri.

\section{Perencanaan Pesan (Konsep Kreatif)}


Konsep kreatif pada media desain katalog ini, penulis mencoba menuangkan ide - ide kreatif berdasarkan data - data yang diperoleh dari PT Global Bangun Mandiri yang kemungkinan diolah dalam sebuah desain sesuai dengan alur proses kreatif yang ada pada setiap lembar halaman dan disesuaikan dengan kebutuhan PT Global Bangun Mandiri

\section{Tujuan Kreatif}

Tujuan kreatif dari perancangan Media Desain Katalog ini adalah untuk menarik perhatian calon konsumen agar dapat menyukai dan meyakinkan terhadap kualitas produk yang tersedia sehingga diharapkan dapat menjalin kerjasama yang baik dan dapat membantu kebutuhan dari para konsumen akan produk properti yang diberikan oleh PT Global Bangun Mandiri.

\section{Tujuan Visual}

Tujuan visualisasi dalam desain katalog adalah untuk mempengaruhi minat konsumen untuk dapat memahami, melihat dan mengerti seluruh informasi yang disampaikan didalam buku. Sedangkan dengan dibuatnya desain katalog, image atau citra yang ditampilkan yaitu dapat menciptakan suatu identitas yang baik dan menjadi perusahaan yang lebih dipercaya eksistensinya oleh masyarakat dan para relasi bisnis PT Global Bangun Mandiri, sehingga dapat menimbulkan image atau citra baru yang baik bagi PT Global Bangun Mandiri sebagai sebuah perusahaan yang bergerak dalam bidang properti. Proses desain katalog ini lebih ditekankan kepada hal-hal yang akan mempengaruhi hasil dari desain yang berkualitas baik, serta mempunyai nilai seni yang tinggi, dengan memperhatikan jenis huruf yang digunakan, gambar yang dipilih lalu ditampilkan dalam desain katalog, unsur warna yang dipilih dan tata letak atau layout yang diterapkan.

\section{Proses Desain (Designing)}

Dalam proses pembuatan desain katalog ini, penulis melakukan secara berurutan sesuai dengan urutan yang telah ditentukan melalui buku panduan, untuk hasil rancangan yang bagus dan efektif penulis menerapkan 3 (tiga) tahapan proses yaitu :

1. Layout Kasar (Rough Layout)

Sebelum membuat rancangan komputer, penulis terlebih dahulu membuat layout kasar dengan mengunakan alat gambar pensil dan kertas untuk memberikan kebebasan penulis dalam menuangkan ide gagasan yang sesuai dengan perancangan, selain itu sebagai pedoman pada saat proses desain dengan menggunakan komputer.

2. Layout Komprehensif

Layout Komprehensif adalah proses desain yang sudah memasuki tahap komputerisasi dan pewarnaan, namun tahap ini belum selesai seluruhnya karena masih harus mengalami proses revisi atau suatu gambar yang sudah mendekati komposisi gambar yang pada umumnya disajikan dalam bentuk warna dan disertai dengan deskripsi rancangan media.

3. Final Artwork

Final Artwork adalah gambar final yang telah melewati layout kasar dan layout komprehensif. Pada proses ini naskah serta tata letak gambar merupakan proses akhir yang siap diproduksi pada proses cetak atau jenis produksi media secara elektronik setelah disempurnakan dengan beberapa kali revisi selama proses desain.

\section{Final Artwork}

1. Final Artwork Cover Depan dan Belakang

Cover depan dengan isi tulisan PT. Global Bangun Mandiri, VISI DAN MISI sedangkan Cover belakang berisi tulisan singkatan GBM, CONTAC US DAN ALAMAT EMAIL perusahaan. Layout warna dasar putih, font yang digunakan pada halaman ini adalah Times New Roman. 

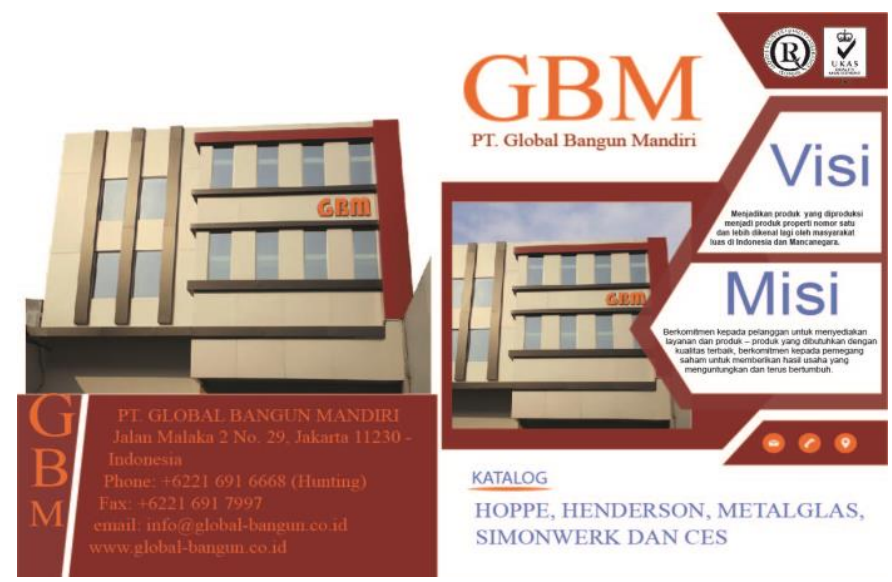

KATALOG

HOPPE, HENDERSON, METALGLAS, SIMONWERK DAN CES

Gambar 1. Final Artwork Cover Depan dan Belakang

2. Final Artwork Halaman 1 dan Halaman 12

Halaman ini adalah beberapa Gambar Produk merk HOPPE, sedangkan Halaman sebelahnya berisi tulisan TENTANG PERUSAHAN serta informasi dari mana produk berasal. Font yang digunakan dalam halaman ini adalah Roboto*



Gambar 2.Final Artwork Halaman 1 dan Halaman 12

3. Final Artwork Halaman 2 dan Halaman 11

Halaman 2 berisi tentang Merk Produk HOPPE, sedangkan halaman 11 berisi tentang perusahaan versi inggris bacaannya ABOUT COMPANY. Font yang digunakan adalah Roboto*

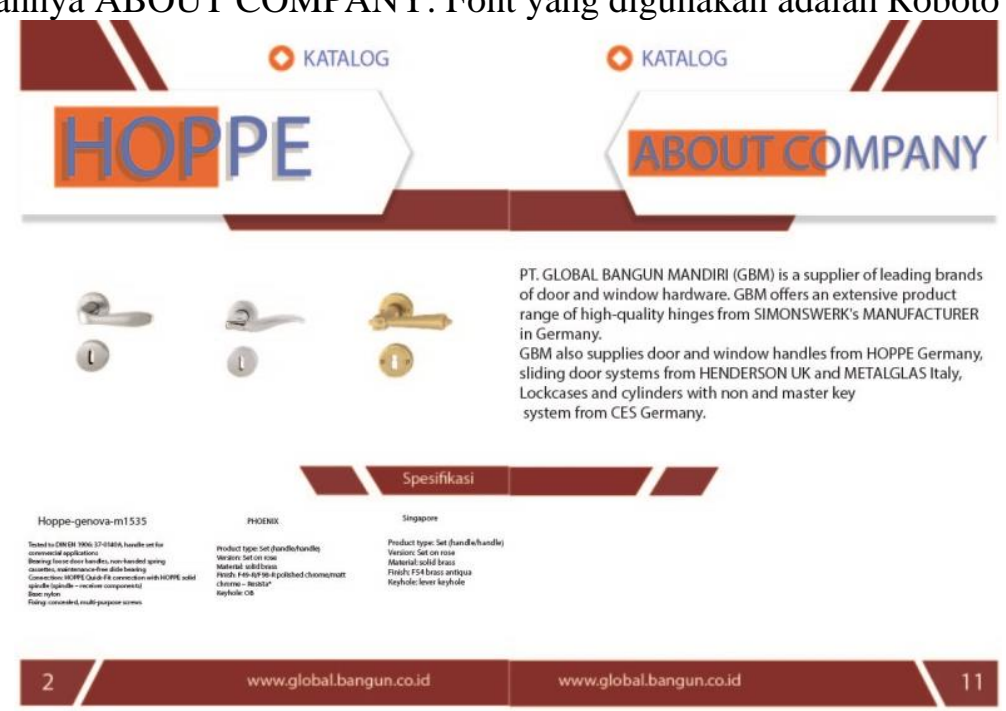

Gambar 3. Final Artwork Halaman 2 dan Halaman 11 
4. Final Artwork Halaman 3 dan Halaman 10

Halaman 4 berisi Produk Merk Henderson dengan fotonya berikut spesifikasi, sedangkan Halaman 10 berisi tentang Produk Merk Ces dengan fotonya berikut spesifikasinya. Font yang digunakan adalah Roboto*

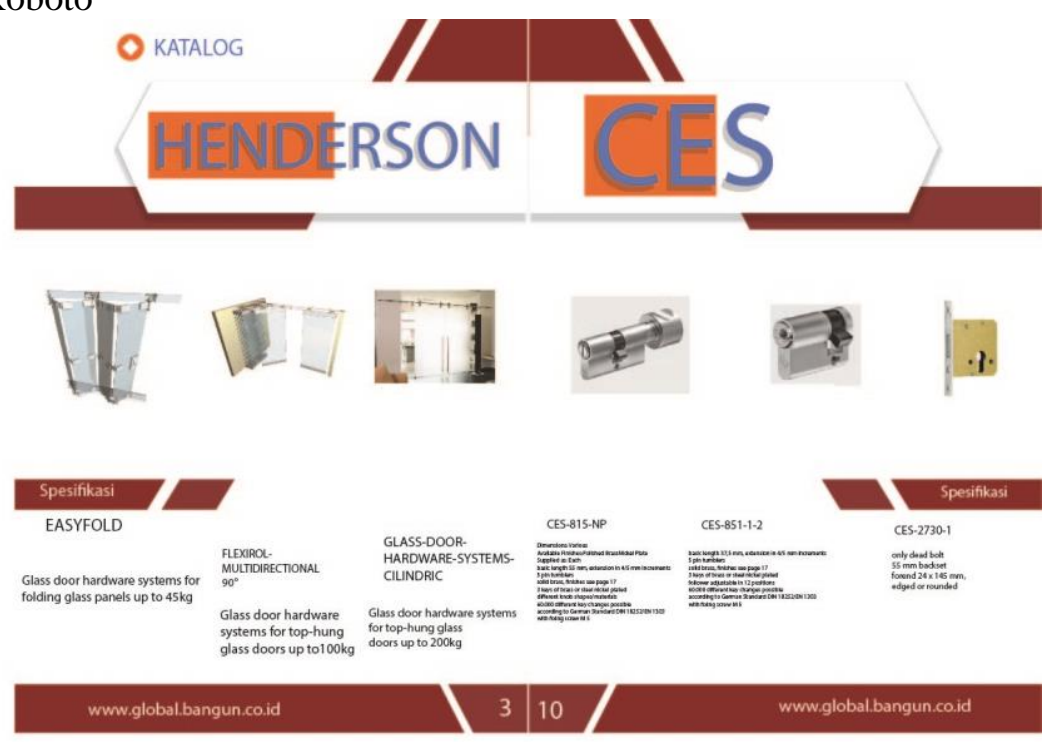

Gambar 4. Final Artwork Halaman 3 dan Halaman 10

5. Final Artwork Halaman 4 dan Halaman 9

Halaman 4 berisi tentang Merk Produk Henderson berikut spesifikasi singkat dari Jenis produk tersebut, sedangkan Halaman 9 berisi produk Ces berikut spesifikasi dari produk Ces tersebut. Font yang digunakan adalah Roboto*



Gambar 5. Final Artwork Halaman 4 dan Halaman 9

6. Final Artwork Halaman 5 dan Halaman 8

Halaman 5 berisi informasi dari Jenis Produk Simonwerk berikut spesifikasi dari produk tersebut. sedangkan Halaman 8 berisi tentang informasi dari Metalglas berikut spesifikasi dari produk tersebut. 
Font yang digunakan adalah Roboto*

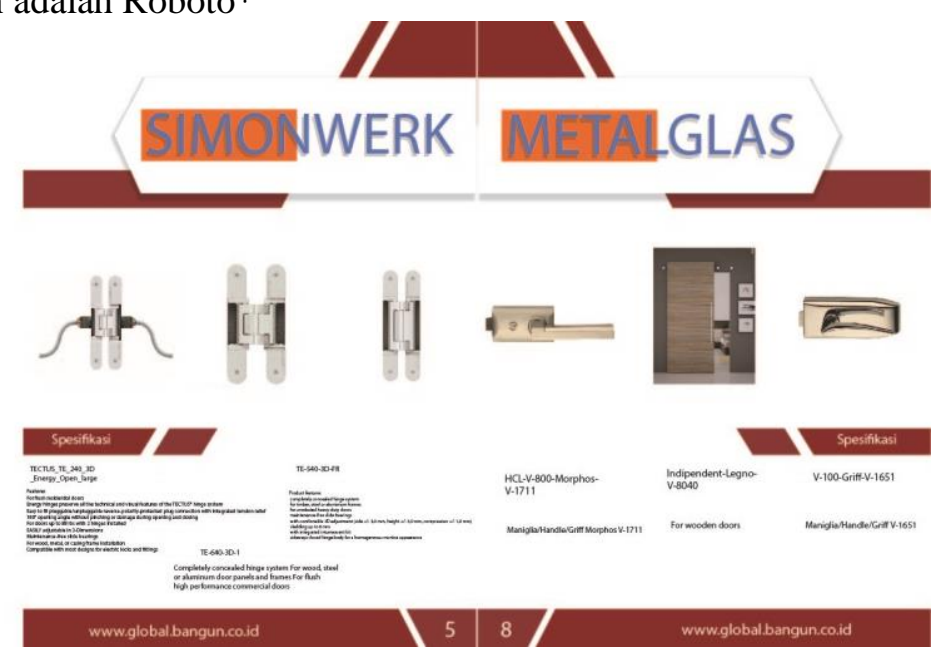

Gambar 6. Final Artwork Halaman 5 dan Halaman 8

7. Final Artwork Halaman 6 dan Halaman 7

Halaman 6 berisi tentang Informasi Produk Merk Simonwerk berikut spesifikasi dari produk juga foto. sedangkan Halaman 7 berisi tentang informasi Produk Merk Metalglas berikut spesifikasi dari produk juga foto. Font yang digunakan adalah Roboto*

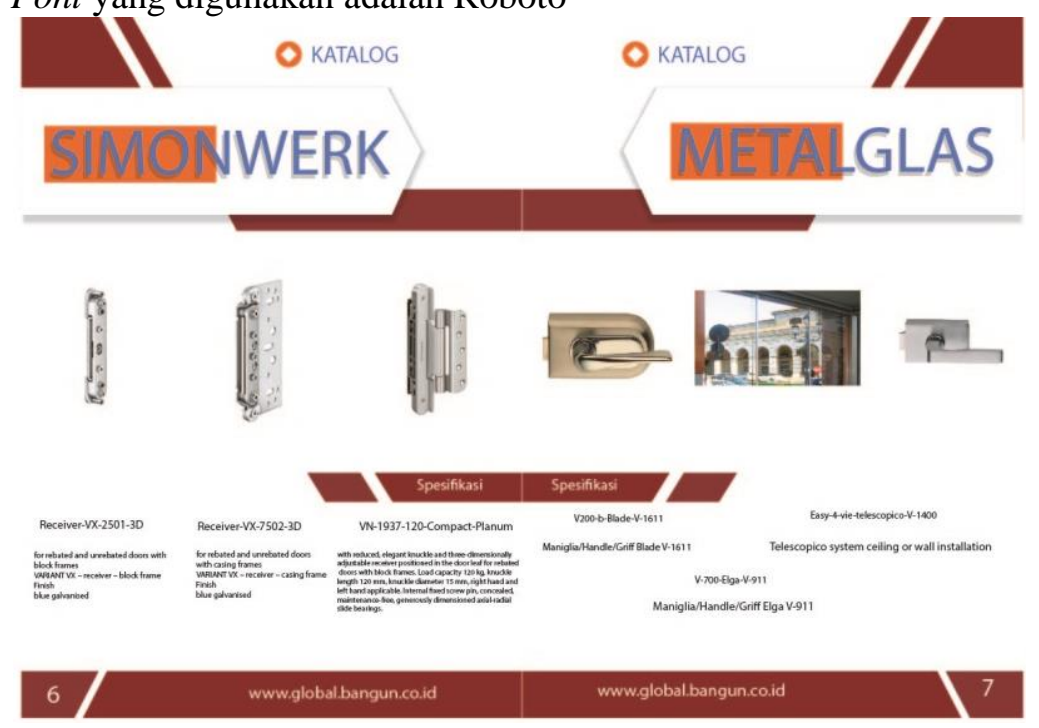

Gambar 7. Final Artwork Halaman 6 dan Halaman 7

\section{KESIMPULAN}

Berdasarkan rumusan masalah yang terkait dengan penelitian yang dilakukan di PT Global Bangun Mandiri dengan membuat Media Desain Katalog sebagai media penunjang informasi dan promosi, maka dapat disimpulkan sebagai berikut:

1. Media yang tepat untuk mempromosikan produk PT Global Bangun Mandiri adalah katalog. Penunjang informasi dan promosi adalah menggunakan katalog. Dimana media tersebut memberikan informasi dan promosi sesuai dengan fungsinya karena itu sangat efektif digunakan guna melengkapi media informasi dan promosi pada PT Global Bangun Mandiri.

2. Merancang media komunikasi visual agar efektif dengan cara media cetak desain berbentuk katalog sebagai media informasi dan promosi visual, dirancang dengan mempertimbangakan teori-teori desain dan kasus yang diangkat, serta berisi 
gambaran dari produk yang elegan. Agar rancangan menarik para konsumen, perancangan konsep desain katalog produk didesain semenarik mungkin mengikuti tren.

3. Manfaat yang didapat setelah adanya desain katalog sebagai penunjang informasi dan promosi pada PT Global Bangun Mandiri yaitu memudahkan para konsumen dalam menerima informasi dan melihat barang promosi bukan dari web yang hanya bisa diakses melalui koneksi internet.

\section{DAFTAR PUSTAKA}

[1] Maimunah, dkk. 2012. Desain Media Komunikasi Visual Sebagai Sarana Penunjang Promosi pada Perguruan Tinggi Raharja, Journal CCIT Vol.3 No.2. Tangerang: Perguruan Tinggi Raharja.

[2] Desrianti, Dewi Immaniar. Sudaryono. Dwi Ayu Ningrum. 2014. Enriching Media Merchandise Sarana Penunjang Promosi Studi Kasus Pada Bookstore, Journal CCIT Vol. 7 No.3 - Mei 2014. Tangerang : Perguruan Tinggi Raharja.

[3] Anggraini S, Nathalia. 2014. Strategi Muslim Designer Community Dalam Mengembangkan Komunikasi Visual Sebagai Media Dakwah, Jakarta: UIN Syarif Hidayatullah.

[4] Mukadar,Winda Tri Astami. Muhamad Bahruddin. Sigit Prayitno Yosep. 2016. Redesain Environmental Graphic Taman Bungkul Surabaya Dengan Teknik Vektor Sebagai Upaya Optimalisasi Media Informasi. Jurnal Art Nouveau Vol.5 No.2. STIKOM Surabaya.

[5] Lifenia, Resita. 2013. Perancangan Media Promosi Triwulan Event Artotel Surabaya. Jurnal DKV Adiwarna Vol.1 No.2. Surabaya: Universitas Kristen Petra. 